\title{
Factors associated with quality of life in nursing home residents with frailty
}

\author{
Enid Wai-yung Kwong ${ }^{1}$, Claudia Kam-yuk Lai ${ }^{1}$, Kin-sun Chan ${ }^{2}$ \\ 1. School of Nursing, The Hong Kong Polytechnic University, Hong Kong, China. 2. University of Macau, Macau, China. \\ Correspondence: Enid Wai-yung Kwong. Address: School of Nursing, The Hong Kong Polytechnic University, Yuk Choi \\ Road, Hung Hom, Hong Kong. Email: hsenid@inet.polyu.edu.hk
}

Received: November 11, 2013

Accepted: January 15, 2014

Online Published: January 23, 2014

DOI : $10.5430 / c n s . v 2 n 2 p 1$

URL: http://dx.doi.org/10.5430/cns.v2n2p1

\section{Abstract}

Aims: The study aimed to examine the prevalence of frailty in nursing home residents and the extent to which personal characteristics and health functioning interactively affects the quality of life (QoL) of nursing home residents with frailty.

Method: This was a cross-sectional survey. Ninety-one nursing home residents who achieved a Rockwood's frailty index score of 1 or above and a Mini Mental State Examination score of 12 or above from two Hong Kong nursing homes participated in this study. The Chinese version of World Health Organization Quality of Life-BREF was used to measure QoL.

Results: The prevalence of frailty in these two nursing homes studied was $31.6 \%$. Four significant factors - pain, sleep quality, performance in activities of daily living (ADL) and fall risk - were identified from four multivariate regression models. Pain and sleep quality were predictive of overall QoL, and these two factors together with performance in ADL determined physical QoL. Painand performance in ADL had an effect on psychological QoL, while fall riskaffected the environmental domain of QoL.

Conclusion: This is the first study to report prevalence of frailty in Chinese older people receiving long-term residential care in Hong Kong. It serves as the ground work to enable nurses to develop nursing strategies to address significant factors to improve the QoL of nursing home residents with frailty.

\section{Key words}

Frailty, Quality of life, Nursing home residents

\section{I ntroduction}

Frailty is a key issue in gerontology. It is commonly considered to be a state of high vulnerability that causes adverse health outcomes including disability, dependency, falls, the need for long-term care, and mortality ${ }^{[1]}$ although there is no consensus definition ${ }^{[2]}$. It is anticipated that the prevalence of frailty in older people will increase because an aging global population and enhanced longevity worldwide allows more older people to live longer with chronic illnesses and long-term disabilities that are often not reversible. Frailty not only decreases people's quality of life (QoL) ${ }^{[3]}$ but also increases their caregivers' burden and health and social cost to society. This impact of frailty has prompted healthcare 
professionals and researchers to pay more attention and make greater efforts to consider strategies to prevent and identify frailty, and to care for older people with frailty.

As nursing homes are often the last resort for older people, especially those of advanced age and/or with impairment, it is normal for many residents in such settings to suffer from frailty. In order to provide quality care to elderly residents with frailty in nursing homes, we have to focus on improving their quality of life $(\mathrm{QoL})$ in addition to increasing their longevity. Knowing the factors associated with their QoL is the first step in planning quality nursing strategies to improve it.

Previous international studies have reported influences on QoL in elderly residents in long-term residential care homes. Nursing home residents who had higher socio-economic status ${ }^{[4]}$ better performance in the activities of daily living ${ }^{[4-7]}$ better physical function ${ }^{[4,5]}$, greater fall efficacy ${ }^{[8]}$, more participation in physical exercise ${ }^{[7]}$, more social support from nursing aids or more interaction with family ${ }^{[4]}$ tended to report better QoL. Their QoL was worse, however, if they had chronic pain ${ }^{[8,9]}$ vision impairment ${ }^{[10]}$ or pressure ulcers ${ }^{[8]}$. Sitoh et al.'s study ${ }^{[11]}$ of residents in nursing homes and hostels found that type of care home (nursing homes), osteoarthritis and Parkinson's disease, previous fractures, and urinary incontinence were factors affecting the health-related QoL of institutionalized elderly people. Apart from these, dining experiences ${ }^{[12]}$ and nursing home characteristics ${ }^{[13]}$ were also associated with the QoL of nursing home residents.

There are several types of residential care settings for residents with varying health status, impairments or disabilities. Nursing home, which is a type of long-term care home, provides care to residents with relatively higher dependence in self-care than those in other types of long-term care homes. However, it is incorrect to assume that nursing home residents are frail in general. Instead, it is necessary to identify those with frailty in nursing home settings and specify their impairments and/or disabilities for identifying factors associated with their QoL. Two previous studies specified which group of nursing home residents was involved in the investigations and clearly identified the types of impairments causing their frailty. Mitchell \& Kemp's study ${ }^{[14]}$ of functionally impaired residents in licensed residential care facilities for older people in Los Angeles and Orange Counties in California reported that monthly family contact, participation in social activities, and low conflict in an environment could improve QoL. Another study of cognitively and functionally impaired residents of Medicare-/Medicaid-certified nursing homes in five states found that urinary incontinence worsened QoL ${ }^{[15]}$.

Personal characteristics

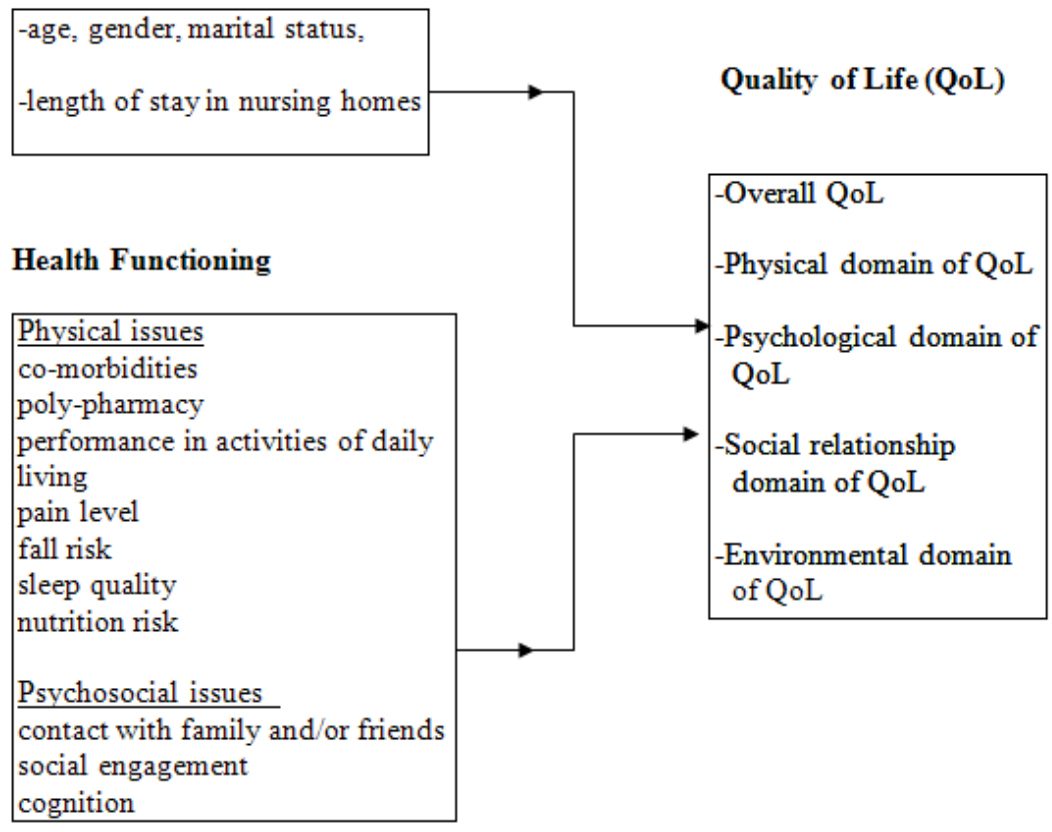

Figure 1. Framework of the study 
In short, the previous empirical data on QoL factors have indicated that health functioning contributed by physical and psychosocial health issues has impact on quality of life in elderly residents receiving long-term care. In addition, the QoL of residents with clearly-identified frailty in long-term residential care homes remains an under-researched area.

\section{Study aims}

This study aimed to examine (1) the prevalence of frailty in nursing homes and (2) the extent to which personal characteristics and health functioning affect the QoL of Chinese residents with frailty in Hong Kong nursing homes. Based on the previous studies reviewed, the framework of this study (see Figure 1) was constructed. It was proposed that personal characteristics of residents and their health functioning contributed by physical and psychosocial health issues are associated with QoL of nursing home residents.

\section{Method}

\subsection{Participants}

This was a cross-sectional survey. It involved a convenience sample of 91 elderly residents from two nursing homes in Hong Kong, operated by Hong Kong non-governmental organizations managed by the Social Welfare Department (SWD) of Hong Kong. Residents in Hong Kong nursing homes managed by the SWD tend to have poor health or physical and/or mild mental disabilities ${ }^{[16]}$, but they are not generally frail. The study criteria were living in the nursing home for at least three months before collecting the data and having achieved a score of 1 or more on Rockwood et al.'s frailty index ${ }^{[17]}$ and a score of at least 12 in the Mini Mental State Examination (MMSE) ${ }^{[18]}$. Long-term care residents with an MMSE cut-off score of 9-10 are able to respond reliably in in-depth interviews on their quality of life ${ }^{[19]}$.

\subsection{Measures}

\subsubsection{Frailty index}

Rockwood et al.'s frailty index ${ }^{[17]}$ was employed to identify eligible participants for this study. It covers four domains (mobility, activities of daily living, continence, and cognition), and identifies four levels of progressive impairment, from level 0 to level 3. Level 0 indicates a non-frail participant, while level 1 indicates those who have bladder incontinence only. Level 2 indicates those who need assistance in mobility or in at least one (two if incontinent) basic activity of daily living (ADL), or who have cognitive impairment without dementia. Level 3 denotes those who are totally dependent on others for transfer or who need assistance in at least two (three if incontinent) basic ADLs, or who have double incontinence and a diagnosis of dementia ${ }^{[17]}$. This scale is short, simple, and user-friendly, and its domains are common health issues faced by older people, particularly those living in long-term residential care homes. It was thus operationally suitable for use in this study to identify nursing home residents with frailty.

\subsubsection{Resident record}

Each resident has his/her own resident record, which is kept in the nursing home in which that resident lives. Each resident record is reviewed periodically to ensure that the data in the record is kept up-to-date. For this study, data on demographics (age, gender, marital status, length of stay in nursing home), co-morbidities, number of medications, performance in activities of daily living (ADL), contact with family and/or friends, and pain level were retrieved from each resident's record. The Chinese version of the Barthel Index was adopted to assess the participants' performance in ADL. The Barthel Index was first published in $1965^{[20]}$ and includes ten items: personal hygiene, bathing, feeding, toileting, stair climbing, dressing, bowel control, bladder control, ambulation or wheelchair, and chair-bed transfer. The scores for each item range from 0 to 5,10, or 15, with 0 indicating total dependence and 5, 10, or 15 indicating degrees of independence. The total possible score is 100 , with higher scores indicating better performance in self-care. The Barthel index was modified by Granger et al. in $1979^{[21]}$ to include $0-10$ points for each item, and Shah et al. ${ }^{[22]}$ standardized the rating criteria and revised 
the scale into a five-point Likert format to improve its discriminative power. The Chinese version of the modified Barthel Index also consists of ten items with a total score of 100, ranging from 0-10 for each item. The higher the total score, the better the performance in self-care. The kappa values for inter-rater reliability for all items ranged from 0.81 to 1.00 , and the Cronbach's alpha for internal consistency was $0.93^{[23]}$. The participants' pain was assessed using the Chinese version of the pain intensity verbal rating scale (C-PIVRS) ${ }^{[24]}$. The C-PIVRS was modified from a reliable and valid verbal rating scale (VRS) ${ }^{[25-27]}$ with various formats including 4-point ${ }^{[28]}$ to 15 -point scales ${ }^{[29-30]}$ with descriptors to describe intensity of pain. In C-PIVRS, there are 11 pain intensity descriptors and faces ranging from 0 (no pain) to 10 (crucifying pain). This pain scale and the visual analog scale (VAS) demonstrated comparable levels of reliability and validity for assessing Chinese people's pain intensity. The test-retest correlation coefficient of the C-PIVRS was $r=0.92$, while that of the VAS was 0.91 . Their intra-class correlation ranged between 0.78 and 0.90 . The factor analysis of these two pain scales reported one single factor for each scale, indicating that both of these pain scales measure the same pain dimension ${ }^{[31]}$.

Chinese Version of World Health Organization Quality of Life-BREF (C-WHOQOL-BREF) The brief version of the WHOQOL (WHOQOL-BREF), which is an abbreviated version of WHOQOL-100 ${ }^{[32]}$, was developed by Harper \& Power on behalf of WHO ${ }^{[33]}$. The psychometric evaluations report good internal consistency and good construct validity ${ }^{[34,35]}$. The QoL of the participants in this study was assessed using the Chinese version of the WHOQOL-BREF, which has previously been validated ${ }^{[36]}$. Out of a total of 26 items, two rate the overall QoL (one item) and overall health condition (one item). The other 24 assess four domains of QoL: seven items in the physical domain, six in the psychological domain, three in the social relationship domain, and eight in the environmental domain. Items are scored on a 5-point Likert scale from 1 to 5 . Higher total scores indicate a better quality of life.

\subsubsection{Chinese version of the St Thomas's Risk Assessment Tool (C-STRATIF)}

The St Thomas's Risk Assessment Tool (STRATIFY) for falls was originally developed by clinicians and researchers in the United Kingdom to predict fall risk ${ }^{[37]}$ and it demonstrated a cut-off score of 2 at the best balance of sensitivity and specificity in the samples of elderly patients, as well as good inter-rater reliability ${ }^{[37-40]}$. It consists of five dichotomous items to assess five risk factors of falls: history of falls, agitation, dependency in transfer and mobility, vision impairment, and frequent toileting. Each item is rated 1 for presence and 0 for absence of a risk factor. In the item of transfer and mobility, dependency in transfer and mobility are separately assessed. The total score for the tool is 5 , ranging from $0-5$. In this study, the validated Chinese version of the modified STRATIFY tool ${ }^{[41]}$ was used to measure the participants' fall risk. Similar to the original scale, it consists of five dichotomous items, and a score of 2 or above indicates a high risk of falling.

\subsubsection{Mini-Nutritional Assessment (MNA)}

The Mini-Nutritional Assessment (MNA) was originally developed to assess nutritional problems for early intervention if needed. It was validated with representative samples of older people worldwide in various healthcare settings ${ }^{[42-45]}$. In this study, the Chinese version of the MNA, which has good reliability and validity ${ }^{[46]}$, was used to assess the participants' risk of suffering from malnutrition. It consists of 18 items in four parts: anthropometric, general, dietary, and self-assessments. Its total score is 30 , ranging from 0 to 30 . A score of less than 18.5 indicates a high risk of malnutrition, a score of between 18.5 and 23.5 points to a mild risk of malnutrition, and scores of more than 23.5 indicate no risk of malnutrition.

\subsubsection{Chinese version of Pittsburgh Sleep Quality I ndex (PSQI)}

The Pittsburgh Sleep Quality Index, which is a self-rated questionnaire, was originally designed to assess sleep quality. It includes 19 items grouped in seven components: subjective sleep quality, sleep latency, sleep duration, habitual sleep efficiency, sleep disturbances, use of sleeping medication, and daytime dysfunction. Each item is equally rated, ranging from 0 to 3. The total score of this index is 21, ranging between 0 and 21. Higher scores indicate worse sleep quality. It demonstrated a balance of sensitivity of $89.6 \%$ and a specificity of $86.5 \%$ in distinguishing good and poor sleepers at the cut-off point of $5^{[47]}$. The psychometric evaluations of the PSQI reported good internal consistency reliability (alpha $=0.8$ ), and good convergent validity $(r=0.69)$ and discriminate validity $(r=0.37)$ across a variety of clinical populations ${ }^{[48]}$. The 
Chinese version of the PSQI was used in this study to assess the subjective sleep quality of the participants in the past month. Similar to the original version, it consists of 19 items in seven components. A cut-off score of 5 yields a balance between a sensitivity of $98 \%$ and a specificity of $55 \%$ in distinguishing good and poor sleepers. Its test-retest reliability coefficient is 0.85 , and its overall reliability coefficient is $0.82-0.83^{[49]}$.

\subsubsection{Chinese version of Social Engagement Scale (SES)}

The social engagement scale (SES), which is a caregiver-rated scale, measures social involvement ${ }^{[50,51]}$. This scale consists of six dichotomous items indicating the presence (1) or absence of the behavior (0) in question. The total score is 6, ranging from 0 to 6 . Higher scores indicate better social engagement. Satisfactory inter-rater reliabilities for these six items for five countries (Denmark $=0.56$, Italy $=0.68$, Iceland $=0.70$, Japan $=0.53$, and the USA $=0.58$ ) were reported in Schroll et al.'s study ${ }^{[51]}$ (1997). The Chinese version of the SES ${ }^{[52]}$ was used to assess participants' involvement in nursing home life and their initiative in participating in social and recreational programs in the previous seven days. Similar to the original scale, it has six dichotomous items with a total score of 6 . In this study, the participants' rating on each item of the scale was assessed based on the reports of nurses or nursing assistants working in the nursing homes.

\subsubsection{Chinese version of Mini Mental State Examination (C-MMSE)}

The MMSE, which is reliable and valid ${ }^{[53,54]}$, was originally designed for use in assessing cognitive function in clinical settings and in research ${ }^{[18]}$. The Chinese version of the MMSE was adopted to identify eligible participants for this study. Seven dimensions of cognition are measured and good reliability and validity has been demonstrated. The scores range from 0 to 30, with higher scores indicating better cognitive function. It has good internal consistency, with a Cronbach's alpha of 0.86 , good test-retest reliability coefficient of 0.78 , and excellent inter-rater reliability (ICC $=0.99)$. A cut-off score of 20 demonstrated the best balance between sensitivity of $97.5 \%$ and specificity of $97.3 \%$ in samples consisting of older people ${ }^{[55]}$.

\subsection{Data collection}

There were 91 participants from nursing homes A and B in the cross-sectional survey. In nursing home A, the data were collected from the participants and the nurses or nursing assistants. A trained research assistant (RA) screened 96 residents in nursing home A and identified 29 who met the study criteria. After obtaining informed written consent from each participant, the RA collected the data through individual face-to-face interviews. During the interview, the RA read out each question and asked each participant to respond, recording his/her response on the form. The RA retrieved the necessary data from each participant's resident record and also collected data on social engagement in nursing home life of the participants from nurses or nursing assistants who were full-time staff, had been providing direct care to the participants for at least six months and were voluntary to provide the data.

In nursing home $\mathrm{B}$, the data were retrieved from a health database of the residents in this nursing home. This database was developed earlier by our research team. It includes up-to-date data on the demographics and the physical, psychosocial, and cognitive health and QoL of 192 residents in nursing home B. As this database contains the necessary data for this study, we retrieved this data from the database, instead of collecting it from the participants in nursing home B and thereby disturbing them. Out of 192 residents in the database, the RA retrieved the necessary data of 62 residents who met the criteria for this study. The data collection methods in nursing homes A and B were different, but the instruments and data collection methods adopted for the development of the database in nursing home B were the same as those employed for collecting the data in nursing home A. Out of 288 residents in two nursing homes, 197 residents (68.4\%) were screened out for this study because they were not frail.

\subsection{Ethical considerations}

Before the commencement of the study, ethical approval was obtained from the Human Ethics Committee of the first author's University. Access approval was obtained from the two nursing homes and approval to retrieve data from the health database was given by nursing home B. Before starting the data collection for the survey, the RA obtained informed 
written consent from participants with MMSE scores of 20 or above and from the family members of those with MMSE scores of 19 or below. The participants were assured that there would be no penalties if they refused to answer any questions or if they withdrew from our study, which they were free to do at any time. They were also given strong assurances of anonymity and confidentiality.

\subsection{Data analysis}

The data were analyzed using IBM's SPSS Statistics software (version 19) ${ }^{[56]}$. The participants' demographics, physical and psychosocial factors, and quality of life (QoL) were analyzed using descriptive statistics that included percentages, frequencies, and mean values. The correlations among independent variables (pain level, age, length of stay, co-morbidities, performance in ADL, agitated behavior, and social engagement), which were measured by either ratio or interval scales and continuous dependent variables (overall QoL and various QoL domains), were investigated using a Pearson correlation analysis. The independent t-test or F-test was used to analyze the bivariate relationship between the continuous dependent variables and the categorical independent variables (gender, marital status, polypharmacy, sleep quality, nutrition risk, contact with family/ friends, having adult children, cognitive function). A univariate analysis of variance was carried out for each independent variable (a total of 14 variables) and each QoL domain to identify statistically significant independent variables. These significant independent variables were then taken to multivariate regression analysis ${ }^{[57]}$ to identify the significant determinants of overall QoL and various QoL domains. The statistical significance level was set at $p<0.05$. The variance inflation factors (VIFs) for five final models were from 1.050 to 1.164 , which was not considered indicative of multicollinearity ${ }^{[58]}$. Adopting the GPOWER program ${ }^{[59]}$, the adjusted R square of 0.148 in the multivariate model of overall QoL (see Table 5), $p$ value at 0.05 and sample size of 91 were used to calculate the power of this study, which was 0.82 .

\section{Results}

\subsection{Participants' characteristics}

A total of 91 residents with a mean age of $80.86(\mathrm{SD}=7.72)$ participated in the study.

Fifty-one participants (56\%) were female and $41(45.1 \%)$ had spouses. They had been living in the nursing homes for an average of 6.9 months $(\mathrm{SD}=3.6)$. Regarding their performance in $\mathrm{ADL}$, they had a mean of $57.57(\mathrm{SD}=27.95)$, indicating high dependence in self-care. Seventy-one (78\%) of them had impaired cognitive function, with MMSE scores of below 20. Regarding their QoL, the mean values of all QoL domains were similar, between 12.0-12.95 (see Table 1).

\subsection{Prevalence of frailty and frailty Level}

Out of 288 participants (nursing home $\mathrm{A}=96$, nursing home $\mathrm{B}=192$ ) in two nursing homes, 91 suffered from frailty (31.6\%). Among those with frailty, none were at a frailty level of 1 , while $55(60.4 \%)$ were at level 2 and $36(39.6 \%)$ were at level 3. The mean ADL score was $74.3(\mathrm{SD}=19.22)$ among participants at level 2 and $32.0(\mathrm{SD}=18.08)$ among those at level 3 , indicating that they were moderately and severely dependent in self-care respectively. Regarding their cognitive function, $45(81.8 \%)$ of them with a frailty level of 2 and $26(72.2 \%)$ at a frailty level of 3 were impaired. Sixty-two participants (68.1\%) needed assistance in transfer and 69 participants $(75.8 \%)$ were dependent in terms of mobility (see Table 2).

\subsection{Correlations among demographics, health factors and QoL}

As shown in Table 3, performance in ADL had a significantly positive relationship with physical $(r=0.22, p=0.04)$ and psychological QoL $(r=0.24, p=0.02)$. Level of pain was negatively related to overall QoL $(r=-0.38, p<0.001)$, physical QoL $(r=-0.43, p<0.001)$, and psychological QoL $(r=-0.31, p=0.003)$. 
Table 1. Participants' characteristics $(\mathrm{N}=91)$

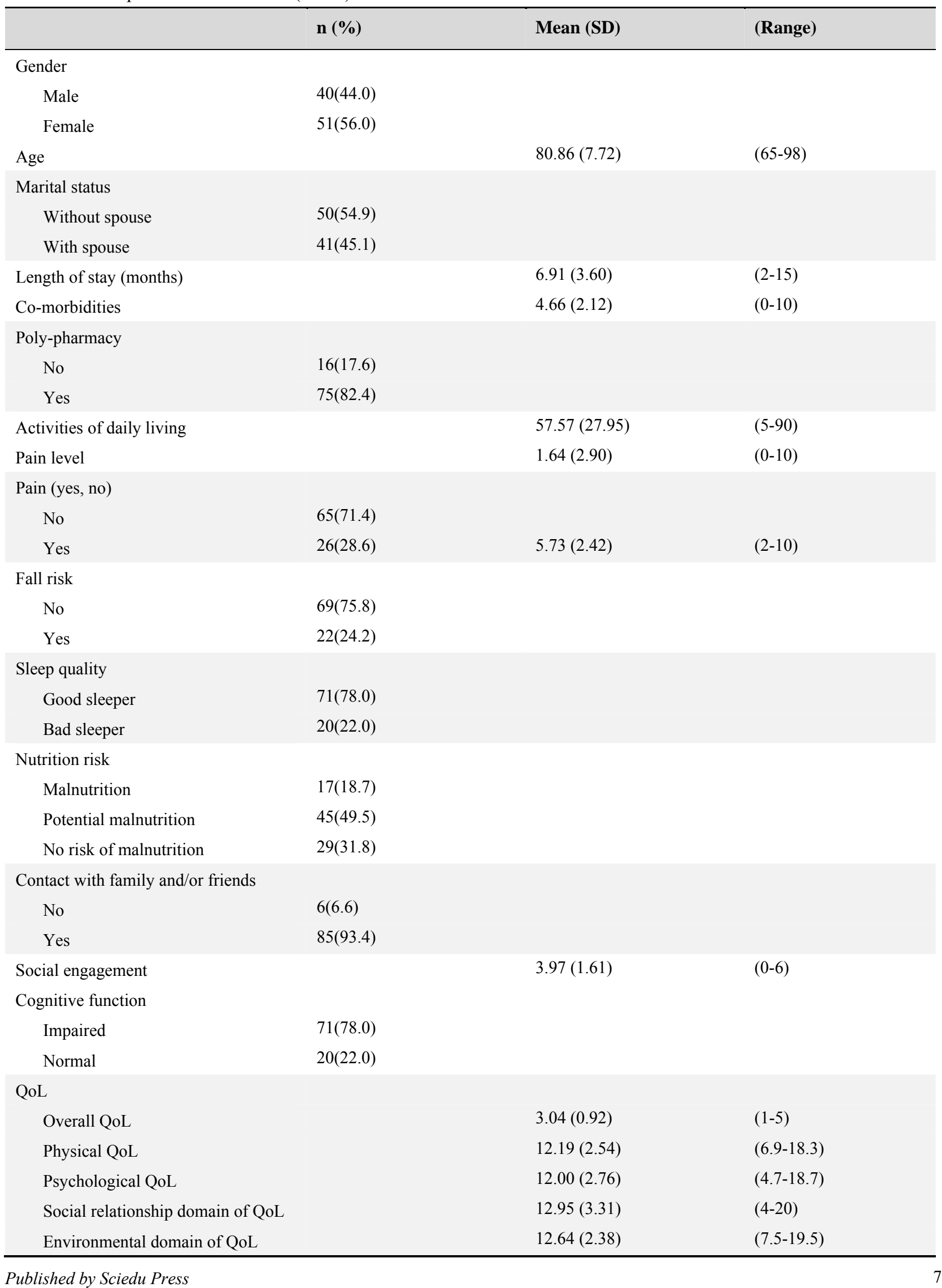


Table 2. Cognitive function, performance in ADL, incontinence and transfer by frailty level

\begin{tabular}{|c|c|c|c|c|c|c|c|}
\hline & & \multicolumn{3}{|c|}{ Level 2 (n=55) } & \multicolumn{3}{|c|}{ Level $3(n=36)$} \\
\hline & & n (\%) & Mean (SD) & (Range) & n (\%) & Mean (SD) & (Range) \\
\hline Age & & $55(60.4)$ & 82.18 (7.49) & $(64-97)$ & $36(39.6)$ & $78.83(7.74)$ & $(65-98)$ \\
\hline $\begin{array}{l}\text { Cognitive } \\
\text { function }\end{array}$ & $\begin{array}{l}\text { Impaired } \\
\text { Normal }\end{array}$ & $\begin{array}{l}45(81.8) \\
10(18.2)\end{array}$ & $16.34(4.06)$ & $(11-25)$ & $\begin{array}{l}26(72.2) \\
10(27.8)\end{array}$ & $18.17(5.20)$ & $(11-28)$ \\
\hline $\begin{array}{l}\text { Performance } \\
\text { in ADL }\end{array}$ & & & $74.30(19.22)$ & $(30-90)$ & & $32.00(18.08)$ & $(5-80)$ \\
\hline \multirow[t]{2}{*}{$\begin{array}{l}\text { Bowel } \\
\text { incontinence }\end{array}$} & Yes & $1(1.8)$ & & & $22(61.1)$ & & \\
\hline & No & $54(98.2)$ & & & $14(38.9)$ & & \\
\hline \multirow{2}{*}{$\begin{array}{l}\text { Bladder } \\
\text { incontinence }\end{array}$} & Yes & $2(3.6)$ & & & $26(72.2)$ & & \\
\hline & No & $53(96.4)$ & & & $10(27.8)$ & & \\
\hline \multirow[t]{5}{*}{ Transfer } & Total dependence & $0(0)$ & & & $13(36.1)$ & & \\
\hline & $\begin{array}{l}\text { Dependence with } \\
\text { maximum assistance }\end{array}$ & $5(9.1)$ & & & $11(30.6)$ & & \\
\hline & $\begin{array}{l}\text { Dependence with } \\
\text { moderate assistance }\end{array}$ & $10(18.2)$ & & & $6(16.7)$ & & \\
\hline & $\begin{array}{l}\text { Dependence with } \\
\text { minimal assistance }\end{array}$ & $15(27.3)$ & & & $2(5.6)$ & & \\
\hline & Independence & $25(45.5)$ & & & $4(11.1)$ & & \\
\hline \multirow[t]{5}{*}{ Mobility } & Total dependence & $3(5.5)$ & & & $27(75.0)$ & & \\
\hline & $\begin{array}{l}\text { Dependence with } \\
\text { maximum assistance }\end{array}$ & $4(7.3)$ & & & $2(5.6)$ & & \\
\hline & $\begin{array}{l}\text { Dependence with } \\
\text { moderate assistance }\end{array}$ & $6(10.9)$ & & & $3(8.3)$ & & \\
\hline & $\begin{array}{l}\text { Dependence with } \\
\text { minimal assistance }\end{array}$ & $23(41.8)$ & & & $1(2.8)$ & & \\
\hline & Independence & $19(24.5)$ & & & $3(8.3)$ & & \\
\hline
\end{tabular}

\subsection{Differences in QoL by demographics and factors}

The participants who were good sleepers reported higher overall QoL $(t=2.180, p=0.04)$ and physical QoL $(t=2.903$, $p=0.005)$ than those who were poor sleepers. Those without fall risk tended to have significantly higher environmental QoL $(t=2.440, p=0.017)$ (see Table 4).

\subsection{Multivariate regression analysis identifying determinants of QoL}

From the univariate analysis of variance, it was found that pain, sleep quality, performance in ADL, gender, and age were significant and could be taken for multivariate regression analysis. Fall risk was not significant in the univariate analysis but it was significant in the independent t-test. In order not to miss any potential determinants of QoL, we also added fall risk to the multivariate regression analysis. Among six significant independent variables, it was found that pain level, 
performance in ADL, sleep quality and fall risk significantly determined overall, physical, psychological and environmental QoL Those participants who were good sleepers $(t=-0.219, \beta=-0.495, p=0.031)$ and reported lower pain levels $(t=-3.052, \beta=-0.101, p=0.003)$ tended to report higher overall QoL. Those who were good sleepers $(t=-2.197$, $\beta=-1.298, p=0.031)$ and had lower pain levels $(t=-3.479, \beta=-0.300 p=0.001)$ and better performance in ADL $(t=2.176$, $\beta=0.019, p=0.032)$ were more likely to report higher physical QoL. Those with lower pain levels $(t=-2.098, \beta=-0.212$, $p=0.039)$ and better performance in $\operatorname{ADL}(t=2.242, \beta=0.023, p=0.028)$ reported higher psychological QoL. Those with no risk of falls $(t=-2.005, \beta=-1.149, p=0.048)$ reported a higher environmental domain of QoL (see Table 5).

Table 3. Correlation matrix of QoL and personal characteristics /health functioning

\begin{tabular}{lllllll}
\hline \multirow{2}{*}{ QoL } & \multicolumn{5}{c}{ Correlation coefficient, $\boldsymbol{r}$} \\
\cline { 2 - 7 } & Pain Level & Age & Length of stay & Co-morbidities & ADL & Social engagement \\
\hline Overall QoL & $-0.38^{\#}$ & 0.10 & 0.10 & -0.12 & 0.05 & -0.09 \\
Physical QoL & $-0.43^{\#}$ & 0.04 & 0.12 & -0.15 & $0.22^{*}$ & -0.18 \\
Psychological QoL & $-0.31^{\#}$ & 0.06 & -0.12 & -0.12 & $0.24^{*}$ & -0.10 \\
Social relationship domain of QoL & 0.01 & 0.02 & -0.15 & -0.11 & 0.07 & 0.09 \\
Environmental domain of QoL & -0.10 & -0.19 & -0.13 & -0.01 & 0.18 & 0.08 \\
\hline
\end{tabular}

${ }^{*} p<0.05 \quad{ }^{*} p<0.01$

\section{Discussion}

\subsection{Prevalence of frailty}

The prevalence of frailty (36.1\%) reported in this study is relatively lower than the figure of $80 \%$ found in a study with 137 residents from two nursing homes and one assisted living facility in La Crosse, Wisconsin ${ }^{[60]}$. Perhaps the length of stay in the nursing homes of this sample is shorter than that in Kanwar et al.'s study ${ }^{[60]}$. The shorter average length of stay is perhaps because home A had been re-organized as a nursing home setting for only around 2.5 years and home B was a new nursing home that had been established for just about 1.5 years at the time of collecting the data. Another possible reason for the big difference in prevalent of frailty reported in this study and Kanwar et al's study is, adopting different measures to identify frailty. In Kanwar et al's study ${ }^{[60]}$, walking speed less than 1 meter per minute and less than 0.6 meter per minute were used to define frailty and the prevalence of $80 \%$ and $60 \%$ respectively reported. The prevalence of frailty in long-term care settings was under reported so it is recommended to examine this area for healthcare planning, policy and interventions. This study sample has physical and/or mental frailty. They had moderate to severe deficiency in ADL, as evidenced by the mean score of ADL. The majority of them are cognitively impaired, with MMSE scores of 20 or below, and needed assistance in transfer and/or mobility.

\subsection{Quality of life}

Among the five regression models of QoL in this study, no significant factors were found in the social relationship domain of the QoL model. There are four significant factors - pain, sleep quality, performance in ADL, and fall risks - that are associated with quality of life in nursing home residents with frailty. Among these factors, sleep quality has the strongest effect on QoL, followed by pain, but pain is the most influential because it is statistically significant in three regression models for overall, physical and psychological QoL, out of four models. The interactive effects of these several significant factors on the QoL of nursing home residents with frailty are discussed below. 
Table 4. Differences in QoL by personal characteristics and health functioning

\begin{tabular}{|c|c|c|c|c|c|c|c|c|c|c|c|c|c|c|c|}
\hline & \multicolumn{3}{|c|}{ Overall QoL } & \multicolumn{3}{|c|}{ Physical QoL } & \multicolumn{3}{|c|}{ Psychological QoL } & \multicolumn{3}{|c|}{$\begin{array}{l}\text { Social relationship } \\
\text { domain of QoL }\end{array}$} & \multicolumn{3}{|c|}{$\begin{array}{c}\text { Environmental domain } \\
\text { of QoL }\end{array}$} \\
\hline & $\begin{array}{l}\text { Mean } \\
\text { (SD) }\end{array}$ & $\begin{array}{l}t- \\
\text { value }\end{array}$ & $\begin{array}{l}p \text { - } \\
\text { value }\end{array}$ & $\begin{array}{l}\text { Mean } \\
\text { (SD) }\end{array}$ & $\begin{array}{l}t- \\
\text { value }\end{array}$ & $\begin{array}{l}p \text { - } \\
\text { value }\end{array}$ & $\begin{array}{l}\text { Mean } \\
\text { (SD) }\end{array}$ & $\begin{array}{l}t- \\
\text { value }\end{array}$ & $\begin{array}{l}p \text { - } \\
\text { value }\end{array}$ & $\begin{array}{l}\text { Mean } \\
\text { (SD) }\end{array}$ & $\begin{array}{l}t- \\
\text { value }\end{array}$ & $\begin{array}{l}p \text { - } \\
\text { value }\end{array}$ & $\begin{array}{l}\text { Mean } \\
\text { (SD) }\end{array}$ & $\begin{array}{l}t- \\
\text { value }\end{array}$ & $\begin{array}{l}p \text { - } \\
\text { value }\end{array}$ \\
\hline \multicolumn{16}{|l|}{ Gender } \\
\hline Male & $\begin{array}{l}3.13 \\
(0.88)\end{array}$ & 0.74 & 0.46 & $\begin{array}{l}13.67 \\
(2.41)\end{array}$ & 1.62 & 0.11 & $\begin{array}{l}12.27 \\
(2.92)\end{array}$ & 0.82 & 0.41 & $\begin{array}{l}12.93 \\
(3.07)\end{array}$ & -0.05 & 0.96 & $\begin{array}{l}12.91 \\
(2.163)\end{array}$ & 0.96 & 0.34 \\
\hline Female & $\begin{array}{l}2.98 \\
(0.95)\end{array}$ & & & $\begin{array}{l}12.81 \\
(2.60)\end{array}$ & & & $\begin{array}{l}11.79 \\
(2.63)\end{array}$ & & & $\begin{array}{l}12.97 \\
(3.53)\end{array}$ & & & $\begin{array}{l}12.43 \\
(2.542)\end{array}$ & & \\
\hline \multicolumn{16}{|c|}{ Marital status } \\
\hline $\begin{array}{l}\text { Without } \\
\text { spouse }\end{array}$ & $\begin{array}{l}3.02 \\
(0.98)\end{array}$ & -0.27 & 0.79 & $\begin{array}{l}13.39 \\
(2.42)\end{array}$ & 0.81 & 0.42 & $\begin{array}{l}12.24 \\
(3.15)\end{array}$ & 0.95 & 0.34 & $\begin{array}{l}13.04 \\
(3.53)\end{array}$ & 0.28 & 0.78 & $\begin{array}{l}12.70 \\
(2.460)\end{array}$ & 0.25 & 0.81 \\
\hline With spouse & $\begin{array}{l}3.07 \\
(0.85)\end{array}$ & & & $\begin{array}{l}12.95 \\
(2.69)\end{array}$ & & & $\begin{array}{l}11.71 \\
(2.20)\end{array}$ & & & $\begin{array}{l}12.85 \\
(3.07)\end{array}$ & & & $\begin{array}{l}12.57 \\
(2.312)\end{array}$ & & \\
\hline \multicolumn{16}{|c|}{ Poly-pharmacy } \\
\hline No & $\begin{array}{l}3.00 \\
(1.07)\end{array}$ & -0.20 & 0.84 & $\begin{array}{l}13.96 \\
(2.33)\end{array}$ & 1.29 & 0.20 & $\begin{array}{l}12.58 \\
(2.63)\end{array}$ & 0.85 & 0.40 & $\begin{array}{l}13.47 \\
(3.71)\end{array}$ & 0.70 & 0.49 & $\begin{array}{l}12.58 \\
(2.456)\end{array}$ & -0.09 & 0.93 \\
\hline Yes & $\begin{array}{l}3.05 \\
(0.90)\end{array}$ & & & $\begin{array}{l}13.04 \\
(2.58)\end{array}$ & & & $\begin{array}{l}11.91 \\
(2.79)\end{array}$ & & & $\begin{array}{l}12.81 \\
(3.25)\end{array}$ & & & $\begin{array}{l}12.64 \\
(2.395)\end{array}$ & & \\
\hline \multicolumn{16}{|l|}{ Fall risk } \\
\hline No & $\begin{array}{l}3.06 \\
(1.01)\end{array}$ & 0.35 & 0.73 & $\begin{array}{l}13.21 \\
(2.53)\end{array}$ & 0.14 & 0.89 & $\begin{array}{l}12.26 \\
(2.74)\end{array}$ & 1.60 & 0.11 & $\begin{array}{l}13.30 \\
(2.99)\end{array}$ & 1.77 & 0.08 & $\begin{array}{l}12.98 \\
(2.356)\end{array}$ & 2.44 & $0.02^{*}$ \\
\hline Yes & $\begin{array}{l}3.00 \\
(0.54)\end{array}$ & & & $\begin{array}{l}13.13 \\
(2.62)\end{array}$ & & & $\begin{array}{l}11.19 \\
(2.70)\end{array}$ & & & $\begin{array}{l}11.88 \\
(4.07)\end{array}$ & & & $\begin{array}{l}11.59 \\
(2.197)\end{array}$ & & \\
\hline \multicolumn{16}{|l|}{ Sleep quality } \\
\hline Good sleeper & $\begin{array}{l}3.18 \\
(0.76)\end{array}$ & 2.18 & $0.04^{*}$ & $\begin{array}{l}13.58 \\
(2.51)\end{array}$ & 2.90 & $0.01^{\#}$ & $\begin{array}{l}12.17 \\
(2.88)\end{array}$ & 1.11 & 0.27 & $\begin{array}{l}12.91 \\
(3.39)\end{array}$ & -0.22 & 0.82 & $\begin{array}{l}12.45 \\
(2.347)\end{array}$ & -1.46 & 0.15 \\
\hline Bad sleeper & $\begin{array}{l}2.55 \\
(1.23)\end{array}$ & & & $\begin{array}{l}11.79 \\
(2.17)\end{array}$ & & & $\begin{array}{l}11.40 \\
(2.25)\end{array}$ & & & $\begin{array}{l}13.10 \\
(3.13)\end{array}$ & & & $\begin{array}{l}13.33 \\
(2.440)\end{array}$ & & \\
\hline \multicolumn{16}{|c|}{ Contact with family and/or friends } \\
\hline No & $\begin{array}{l}3.17 \\
(1.33)\end{array}$ & 0.34 & 0.74 & $\begin{array}{l}12.76 \\
(1.52)\end{array}$ & -0.43 & 0.67 & $\begin{array}{l}11.00 \\
(1.45)\end{array}$ & -0.92 & 0.36 & $\begin{array}{l}12.22 \\
(2.14)\end{array}$ & -0.56 & 0.58 & $\begin{array}{l}12.12 \\
(1.77)\end{array}$ & -0.55 & 0.58 \\
\hline Yes & $\begin{array}{l}3.04 \\
(0.89)\end{array}$ & & & $\begin{array}{l}13.22 \\
(2.60)\end{array}$ & & & $\begin{array}{l}12.07 \\
(2.82)\end{array}$ & & & $\begin{array}{l}13.00 \\
(3.39)\end{array}$ & & & $\begin{array}{l}12.68 \\
(2.42)\end{array}$ & & \\
\hline \multicolumn{16}{|c|}{ Cognitive function } \\
\hline Impaired & $\begin{array}{l}3.01 \\
(0.95)\end{array}$ & -0.58 & 0.56 & $\begin{array}{l}13.29 \\
(2.60)\end{array}$ & 0.70 & 0.49 & $\begin{array}{l}12.13 \\
(2.78)\end{array}$ & 0.85 & 0.40 & $\begin{array}{l}13.18 \\
(3.26)\end{array}$ & 1.26 & 0.21 & $\begin{array}{l}12.70 \\
(2.45)\end{array}$ & 0.46 & 0.65 \\
\hline \multirow[t]{2}{*}{ Normal } & $\begin{array}{l}3.15 \\
(0.81)\end{array}$ & & & $\begin{array}{l}12.84 \\
(2.35)\end{array}$ & & & $\begin{array}{l}11.54 \\
(2.70)\end{array}$ & & & $\begin{array}{l}12.13 \\
(3.46)\end{array}$ & & & $\begin{array}{l}12.43 \\
(2.16)\end{array}$ & & \\
\hline & & $\mathrm{F}$ & $\begin{array}{l}p- \\
\text { value }\end{array}$ & & $\mathrm{F}$ & $\begin{array}{l}p- \\
\text { value }\end{array}$ & & $\mathrm{F}$ & $\begin{array}{l}p \text { - } \\
\text { value }\end{array}$ & & $\mathrm{F}$ & $\begin{array}{l}p \text { - } \\
\text { value }\end{array}$ & & $\mathrm{F}$ & $\begin{array}{l}p- \\
\text { value }\end{array}$ \\
\hline \multicolumn{16}{|l|}{$\begin{array}{l}\text { Nutrition } \\
\text { risk }\end{array}$} \\
\hline Malnutrition & 3.00 & 0.45 & 0.64 & 12.46 & 1.36 & 0.26 & 11.22 & 0.86 & 0.43 & 13.02 & 0.06 & 0.94 & 12.12 & 0.58 & 0.56 \\
\hline & $(0.71)$ & & & $(2.95)$ & & & $(3.16)$ & & & $(3.54)$ & & & $(2.49)$ & & \\
\hline $\begin{array}{l}\text { Potential } \\
\text { malnutrition }\end{array}$ & $\begin{array}{l}3.13 \\
(0.99)\end{array}$ & & & $\begin{array}{l}13.59 \\
(2.57)\end{array}$ & & & $\begin{array}{l}12.23 \\
(2.88)\end{array}$ & & & $\begin{array}{l}12.83 \\
(2.73)\end{array}$ & & & $\begin{array}{l}12.85 \\
(2.11)\end{array}$ & & \\
\hline $\begin{array}{l}\text { No risk of } \\
\text { malnutrition }\end{array}$ & $\begin{array}{l}2.93 \\
(0.92)\end{array}$ & & & $\begin{array}{l}12.99 \\
(2.19)\end{array}$ & & & $\begin{array}{l}12.12 \\
(2.28)\end{array}$ & & & $\begin{array}{l}13.10 \\
(4.05)\end{array}$ & & & $\begin{array}{l}12.62 \\
(2.73)\end{array}$ & & \\
\hline
\end{tabular}

\subsection{Pain, performance in ADL and sleep quality}

This study has confirmed the roles of pain ${ }^{[5-7]}$ and performance in ADL ${ }^{[8,9]}$ in predicting the QoL of nursing home residents, including those with frailty. The findings of this study have shown that pain and performance in ADL affect the psychological QoL of frail nursing home residents and, together with sleep quality, also have an effect on their physical 
QoL. A possible explanation is that pain directly decreases performance in ADL and also indirectly decreases performance in ADL through sleep quality, which results in decreased psychological and physical QoL respectively. Compared with frail nursing home residents without pain, those with pain have more difficulties in mobility and physical activity, resulting in greater risk of developing muscle atrophy, falling, injuring themselves ${ }^{[61,62]}$, and eventually having more deficiency in ADL, which is associated with decreased QoL ${ }^{[6-8]}$. In addition, some kinds of comorbidity cause pain in older people. For example, osteoarthritis, perhaps as a result of pain, decreased performance in ADL, resulting in decreased QoL, as reported in a study by DuBeau et al ${ }^{[15]}$.

Table 5. Multivariate regression analysis predicting QoL

\begin{tabular}{|c|c|c|c|c|c|c|c|c|c|c|c|c|c|c|c|}
\hline & \multicolumn{3}{|c|}{ Overall QoL } & \multicolumn{3}{|c|}{ Physical QoL } & \multicolumn{3}{|c|}{ Psychological QoL } & \multicolumn{3}{|c|}{$\begin{array}{l}\text { Social relationship } \\
\text { domain of QoL }\end{array}$} & \multicolumn{3}{|c|}{$\begin{array}{c}\text { Environmental domain } \\
\text { of QoL }\end{array}$} \\
\hline & $\beta$ & $t$ & $p$ & $\beta$ & $t$ & $p$ & $\beta$ & $t$ & $p$ & $\beta$ & $t$ & $p$ & $\beta$ & $t$ & $p$ \\
\hline $\begin{array}{l}\text { Gender } \\
\text { (male) }\end{array}$ & -0.117 & -0.602 & 0.549 & -0.895 & -1.761 & 0.082 & -0.579 & -0.973 & 0.333 & 0.006 & 0.008 & 0.994 & -0.303 & -0.587 & 0.559 \\
\hline Age & 0.009 & 0.708 & 0.481 & 0.010 & 0.298 & 0.766 & 0.013 & 0.334 & 0.739 & 0.009 & 0.174 & 0.862 & -0.063 & -1.921 & 0.058 \\
\hline $\begin{array}{l}\text { Pain } \\
\text { level }\end{array}$ & -0.101 & -3.052 & $0.003^{\#}$ & -0.300 & -3.479 & $0.001^{\mathfrak{E}}$ & -0.212 & -2.098 & $0.039^{*}$ & 0.063 & 0.483 & 0.630 & -0.080 & -0.914 & 0.363 \\
\hline $\begin{array}{l}\text { Sleep } \\
\text { quality } \\
\text { (good } \\
\text { sleeper) }\end{array}$ & -0.495 & -2.190 & $0.031^{*}$ & -1.298 & -2.197 & $0.031^{*}$ & -0.618 & -0.894 & 0.374 & -0.188 & -0.211 & 0.834 & 0.832 & 1.389 & 0.168 \\
\hline $\begin{array}{l}\text { Fall risk } \\
\text { (no fall } \\
\text { risk) }\end{array}$ & -0.034 & -0.156 & 0.877 & 0.063 & 0.111 & 0.912 & -0.928 & -1.404 & 0.164 & -1.513 & -1.772 & 0.080 & -1.149 & -2.005 & $0.048^{*}$ \\
\hline Intercept & 2.647 & 2.632 & 0.010 & 12.589 & 4.787 & 0.000 & 10.703 & 3.479 & 0.001 & 12.026 & 3.027 & 0.003 & $\begin{array}{l}17.18 \\
3\end{array}$ & 6.446 & 0.000 \\
\hline $\begin{array}{l}\text { Adjusted } \\
\mathrm{R}^{2}\end{array}$ & 0.143 & & & 0.234 & & & 0.110 & & 0.026 & & & & 0.106 & & \\
\hline
\end{tabular}

Pain also decreases the sleep quality of older people ${ }^{[63]}$, leading to poorer moods and a decrease in attention, energy, and performance in $\mathrm{ADL}{ }^{[64-67]}$. Lo \& Lee's study ${ }^{[68]}$ reported that sleep quality was negatively associated with health-related quality of life in Hong Kong Chinese older people in the community, but no studies have investigated this association in long-term care homes. This study reveals for the first time the importance of sleep quality in contributing to the QoL of nursing home residents with frailty. Frail nursing home residents' decreased performance in ADL caused by pain and/or sleep quality will lead to increased deficiencies in self-care and increased dependence on staff caregivers' daily care. This situation will likely decrease their self-esteem and life satisfaction and also increase the likelihood that they will be provided with undignified care. All these may cause decreased psychological QoL.

\subsection{Fall risk}

This study has affirmed the importance of fall risk in determining the QoL of nursing home residents ${ }^{[8]}$, including those with frailty. As reported in this study, fall risk is predictive of the environmental domain of QoL in nursing home residents with frailty. Because of this risk, frail residents may perceive that they are physically unsafe and be afraid to walk, resulting in decreased mobility and activity. To prevent falls, they may also have fewer opportunities to participate in physical and leisure activities because they refuse to do so or nursing home staff do not arrange for their participation. All these factors will in turn impair their environmental QoL.

\subsection{Clinical nursing implications}

The pain of frail residents with deficiency in ADL and/or impaired cognitive function is more likely to be under-identified and under-treated because the deterioration of their physical and communication abilities impairs their ability to communicate pain and the effect of pain management. Nursing home caregivers may overlook and/or be deficient in the 
necessary knowledge and skills to read the body language of this group of residents with regard to the expression of pain. Strategies to enhance the communication of pain between frail residents and caregivers are warranted for the early diagnosis and timely and adequate treatment of pain. Apart from adequate and dignified assistance in their ADL, it is necessary to develop a physical exercise program to prevent muscle atrophy and improve muscle tone and strength in nursing home residents with physical and/or mental frailty. For improvement of sleep quality, it is recommended that resident, daily care and environment factors associated with sleep quality be assessed. Appropriate nursing strategies should then be developed based on these assessment results, in order to manage the factors identified for improvement of QoL in residents with frailty in nursing home settings. Apart from considering nursing strategies to improve QoL, nurses are strongly recommended to adopt a valid, reliable and user-friendly tool to identify nursing home residents at different levels of frailty. Together with other health professionals in nursing homes, nurses should design appropriate care strategies to prevent nursing home residents progressing to higher level of frailty or reverse them to lower level of frailty.

\subsection{Limitations of the study}

There are limitations to this study. The data retrieved from the residents' records were collected from nurses and social workers in the two nursing homes. Although these nurses and social workers were well trained in the use of the instruments and used them frequently to assess the health of their residents, the inter-rater reliability of the instruments was not assessed. In addition, private nursing homes were excluded from this study. In spite of these limitations, the findings can be applied to nursing home residents with frailty in the areas of ADL deficiency and cognitive impairment elsewhere, in long-term residential care settings whose characteristics and those of the residents are similar to this study setting and those of this study sample respectively.

\section{Conclusion}

This is the first study to report prevalence and level of frailty in Chinese older people living in Hong Kong long-term residential care homes. Unlike the previous studies investigating QoL as a whole, this study identified the factors associated with overall QoL and also specific domains of QoL in nursing home residents with frailty. It has confirmed that pain, performance in ADL and fall risk are predictive of QoL among nursing home residents, including those with frailty, and also reveals for the first time the role of sleep quality in explaining the overall QoL and physical QoL of nursing home residents with frailty. New knowledge has been added to the area of frailty and quality of life. The findings of this study have served as groundwork for the development of nursing strategies by addressing the factors identified to improve the QoL of nursing home residents with frailty. For further studies, it is recommended to add nursing home characteristics, living environment and mode of care as factors for investigation, with a larger and more diverse sample to increase the variance of the multivariate regression models. These models will lead to further development of a QoL model better able to explain the QoL of elderly residents with frailty in long-term residential care homes.

\section{Funding}

This study was funded by the Departmental Research Fund of the School of Nursing, the Hong Kong Polytechnic University.

\section{Conflict of interest}

The authors declare no conflict of interest.

\section{References}

[1] Fried LP, Ferrucci L, Darer J, Williamson JD, Anderson G. Untangling the concepts of disability, frailty and comorbidity: Implications for improved targeting and care. Journal of Gerontology: Medical Sciences. 2004; 59(3): 255-263. 
[2] Fried LP, Tangen CM, Walton J, Newman AB, Hirsch C, Gottdiener J, Seeman T, Tracy R, Kop WJ, Burke G, McBurnie MA. Frailty in older adults. The Journals of Gerontology: Series A, Biological Sciences and Medical Sciences. 2001; 56(3): M146-M157. http://dx.doi.org/10.1093/gerona/56.3.M146

[3] Kanauchi M, Kubo A, Kanauchi K, Saito Y. Frailty, health-related quality of life and mental well-being in older adults with cardiometabolic risk factors. International Journal of Clinical Practice. 2008; 62(9): 1447-1451. http://dx.doi.org/10.1111/j.1742-1241.2008.01830.x

[4] Tseng SZ \& Wang RH. Quality of life and related factors among elderly nursing home residents in Southern Taiwan. Public Health Nursing. 2001; 18(5): 304-311. http://dx.doi.org/10.1046/j.1525-1446.2001.00304.x

[5] Ballard C, O’Brien J, James I, Mynt P, Lana M, Potkins D, Reichelt K, Lee L, Swann A, Fossey J. Quality of life for people with dementia living in residential and nursing home care: the impact of performance on activities of daily living, behavioral and psychological symptoms, language skills, and psychotropic drugs. International Psychogeriatrics. 2001; 13(1): 93-106. http://dx.doi.org/10.1017/S1041610201007499

[6] Luleci E, Hey W, Subasi F. Assessing selected quality of life factors of nursing home residents in Turkey. Archives of Gerontology and Geriatrics. 2007; 46(1): 57-66. http://dx.doi.org/10.1016/j.archger.2007.02.007

[7] Degenholtz H, Rosen J, Castle N, Mittal V, Liu D. The association between changes in health status and nursing home resident quality of life. The Gerontologist. 2008; 48(5): 584-592. http://dx.doi.org/10.1093/geront/48.5.584

[8] Kato C, Ida K, Kawamura M, Nagaya M, Tokuda H, Tamakoshi A \& Harada A. Relation of falls efficacy scale (FES) to quality of life among nursing home female residents with comparatively intact cognitive function in Japan. Nagoya Journal of Medical Science. 2008; 70(1-2): 19-27.

[9] Zanocchi M, Maero B, Nicola E, Martinelli E, Luppino A, Gonella M, Gariglio F, Fissore L, Bardelli B, Obialero R \& Molaschi M. Chronic pain in a sample of nursing home residents: prevalence, characteristics, influence on quality of life (QoL). Archives of Gerontology and Geriatrics. 2008; 47(1): 121-128. http://dx.doi.org/10.1016/j.archger.2007.07.003

[10] Elliott AF, McGwin G, Owsley C. Health-related quality of life and visual and cognitive impairment among nursing home residents. British Journal of Ophthalmology. 2009; 93(2): 240-243. http://dx.doi.org/10.1136/bjo.2008.142356

[11] Sitoh YY, Lau TC, Zochling J, Schwarz J, Chen JS, March LM, Cumming RG, Lord SR, Sambrook PN, Cameron ID. Determinants of health-related quality of life in institutionalized older persons in northern Sydney. Internal Medicine Journal 2005; 35(2): 131-134. http://dx.doi.org/10.1111/j.1445-5994.2004.00742.x

[12] Carrier N, West GE, Ouellet D. Dining experience, food services and staffing are associated with quality of life in elderly nursing home residents. The Journal of Nutrition, Health \& Aging. 2009; 13(6): 565-570. http://dx.doi.org/10.1007/s12603-009-0108-8

[13] Xu D, Kane RL \& Shamliyan TA. Effect of nursing home characteristics on residents' quality of life: A systematic review. Archives of Gerontology and Geriatrics. 2013; 57(2): 127-142. http://dx.doi.org/10.1016/j.archger.2013.03.015

[14] Mitchell J, Kemp BJ. Quality of life in assisted living homes: A multidimensional analysis. Journal of Gerontology: Psychological Sciences. 2000; 55(2): 117-127. http://dx.doi.org/10.1093/geronb/55.2.P117

[15] DuBeau CE, Simon SE, Morris JN. The effect of urinary incontinence on quality of life in older nursing home residents. Journal of the American Geriatrics Society. 2006; 54(9): 1325-1333. http://dx.doi.org/10.1111/j.1532-5415.2006.00861.x

[16] Social Welfare Department. Services for the Elderly, Social Welfare Department [Internet]. 2012. Available from: http://www.swd.gov.hk/en/index/site_pubsvc/page_elderly/

[17] Rockwood K, Stadnyk K, MacKnight C, McDowell I, Hébert R, Hogan DB. A brief clinical instrument to classify frailty in elderly people. Lancet. 1999; 353(9148): 205-206. http://dx.doi.org/10.1016/S0140-6736(98)04402-X

[18] Folstein MF, Folstein SE, McHugh PR. "Mini-mental state". A practical method for grading the cognitive state of patients for the clinician. Journal of Psychiatric Research. 1975; 12 (3): 189-198. http://dx.doi.org/10.1016/0022-3956(75)90026-6

[19] Mozley CG, Huxley P, Sutcliffe C, Bagley H, Burns A, Challis D, Cordingley L. 'Not knowing where I am does not mean I do not know what I like': Cognitive impairment and quality of life response in elderly people. International Journal of Geriatric Psychiatry. 1999; 14(9): 776-783. http://dx.doi.org/10.1002/(SICI)1099-1166(199909)14:9<776::AID-GPS13>3.0.CO;2-C

[20] Mahoney FI \& Barthel DW. Functional evaluation: the Barthel Index. Maryland state medical journal. 1965; $14: 61-65$.

[21] Granger CV, Dewis LS, Peters NC, Sherwood CC \& Barrett JE. Stroke rehabilitation: analysis of repeated Barthel index measures. Archives of Physical Medicine and Rehabilitation. 1979; 60(1): 14-7.

[22] Shah S, Vanclay F, Cooper B. Improving the sensitivity of the Barthel Index for stroke rehabilitation. Journal of Clinical Epidemiology. 1989; 42 (8): 703-9. http://dx.doi.org/10.1016/0895-4356(89)90065-6

[23] Leung SO, Chan CC \& Shah S. Development of a Chinese version of the Modified Barthel Index - validity and reliability. Clinical Rehabilitation. 2007; 21(10): 912-922. http://dx.doi.org/10.1177/0269215507077286

[24] Chung JW, Wong CH, Yang JC \& Wong TK. The construction of a pain intensity verbal rating scale in Chinese. Acta Anaesthesiologica Taiwanica. 1999; 37(2): 65-71. 
[25] Price DD, McGrath PA, Rafii A, Buckingham B. The validation of visual analogue scales as ratio scale measures for chronic and experimental pain. Pain. 1983; 17(1): 45-56. http://dx.doi.org/10.1016/0304-3959(83)90126-4

[26] McGuire DB. The measurement of clinical pain. Nursing Research. 1984; 33(3): 152-156. http://dx.doi.org/10.1097/00006199-198405000-00007

[27] Jensen MP, Karoly P. Self-report scales and procedures for assessing pain in adults. In: Turk DC, Melzack R, eds. Handbook of pain assessment. New York: Guildford Press. 2011: 19-44.

[28] Seymour RA. The use of pain scales in assessing the efficacy of analgesics in post-operative dental pain. European Journal of Clinical Pharmacology. 1982; 23(5): 441-4. http://dx.doi.org/10.1007/BF00605995

[29] Gracely RH, McGrath P, Dubner R. Ratio scales of sensory and affective verbal descriptors. Pain. 1978; 5(1): 5-18. http://dx.doi.org/10.1016/0304-3959(78)90020-9

[30] Gracely RH, McGrath P, Dubner R. Validity and sensitivity of ratio scales of sensory and affective verbal descriptors: manipulation of affect by diazepam. Pain. 1978; 5(1): 19-29. http://dx.doi.org/10.1016/0304-3959(78)90021-0

[31] Liu JYW, Chung JWY, Wong TKS. The psychometric properties of the Chinese Pain Intensity Verbal Rating Scale. Acta Anaesthesiologica Scandinavia. 2003; 47: 1010-1019. http://dx.doi.org/10.1034/j.1399-6576.2003.00192.x

[32] WHOQOL Group. Development of the WHOQOL: rationale and current status. International Journal of Mental Health. 1994; 23: 24-56.

[33] Harper A, Power M, WHOQOL Group. Development of the World Health Organization WHOQOL-BREF quality of life assessment. Psychological Medicine. 1998; 28: 551-558. http://dx.doi.org/10.1017/S0033291798006667

[34] Yao G, Chung CW, Yu CF, Wang JD. Development and verification of validity and reliability of the WHOQOL-BREF Taiwan version. Journal of the Formosan Medical Association. 2002; 101(5): 342-51.

[35] Skevington SM, Lotfy M, O'Connell KA, WHOQOL Group. The World Health Organization's WHOQOL-BREF quality of life assessment: psychometric properties and results of the international field trial. A report from the WHOQOL group. Quality of Life Researc. 2004; 13(2): 299-310. http://dx.doi.org/10.1023/B:QURE.0000018486.91360.00

[36] Leung KF, Wong WW, Tay MS, Chu MM, Ng SS. Development and validation of the interview version of the Hong Kong Chinese WHOQOL-BREF. Quality of Life Research. 2005; 14(5): 1413-1419. http://dx.doi.org/10.1007/s11136-004-4772-1

[37] Oliver D, Britton M, Martin FC \& Hopper AH. Development and evaluation of evidence based risk assessment tool (STRATIFY) to predict which elderly inpatients will fall: case-control and cohort studies. British Medical Journal. 1997; 315(7115): 1049-1053. http://dx.doi.org/10.1136/bmj.315.7115.1049

[38] Jester R, Wade S, Henderson K. A pilot investigation of the efficacy of falls risk assessment tools and prevention strategies in an elderly hip fracture population. Journal of Orthopaedic Nursing. 2005; 9(1): 27-34.

http://dx.doi.org/10.1016/j.joon.2004.10.002

[39] Coker E, Oliver D. Evaluation of the STRATIFY falls prediction tool on a geriatric unit. Outcomes Management. 2003 ; $7(1)$ : 8-14.

[40] Vassallo M, Stockdale R, Sharma JC. A comparative study of the use of four fall risk assessment tools on acute medical wards. Journal of American Geriatrics Society. 2005; 53(6): 1034-1035. http://dx.doi.org/10.1111/j.1532-5415.2005.53316.x

[41] Community Geriatric Assessment Team. Validation of the Modified STRATIFY Falls Prediction Tool. Caritas Medical Centre, Community Geriatric Assessment Team. 2010.

[42] Vellas BJ, Guigoz Y, Garry PJ, Albarede JL eds. The Mini Nutritional Assessment: MNA. Nutrition in the elderly, Paris: Serdi Publishing Company. 1997: 15-60.

[43] Guigoz Y, Vellas B. The Mini Nutritional Assessment (MNA) for grading the nutritional state of elderly patients: presentation of the MNA, history and validation. In: Mini Nutritional Assessment (MNA): Research and Practice in the Elderly. Nestlé New Nutrition Workshop Series, Clinical \& Performance Programme 1-2. 1997.

[44] Garry PJ, Vellas B. Practical and validated use of the Mini-Nutritional Assessment in geriatric evaluation. Nutrition in Clinical Care. 1999; 2: 146-154. http://dx.doi.org/10.1046/j.1523-5408.1999.00108.x

[45] Guigoz Y. The mini-nutritional assessment review of the literature - What does it tell us? The Journal of Nutrition, Health and Aging. 2006; 10(6): 468-487.

[46] Hui WH, Law CB, So KY. Validating a modified version of the mini-nutritional assessment in institutionalized elderly Chinese people. Hong Kong Journal of Gerontology. 2001; 15: 35-43.

[47] Buysse DJ, Reynolds CF, Monk TH, Berman SR, Kupfer DJ. The Pittsburgh Sleep Quality Index: a new instrument for psychiatric practice and research. Psychiatry Research. 1989; 28(2): 193-213. http://dx.doi.org/10.1016/0165-1781(89)90047-4

[48] Carpenter JS, Andrykowski MA. Psychometric evaluation of the Pittsburgh Sleep Quality Index. Journal of Psychosomatic Research. 1998; 45(1): 5-13. http://dx.doi.org/10.1016/S0022-3999(97)00298-5

[49] Tsai PS, Wang SY, Wang MY, Su CT, Yang TT, Huang CJ \& Fang SC. Psychometric evaluation of the Chinese version of the Pittsburgh Sleep Quality Index (CPSQI) in primary insomnia and control subjects. Quality of Life Research. 2005; 14(8): 1943-1952. http://dx.doi.org/10.1007/s11136-005-4346-x 
[50] Mor V, Branco K, Fleishman J, Hawes C, Phillips C, Morris J, Fries B. The structure of social engagement among nursing home residents. The Journals of Gerontology. Series B, Psychological Sciences and Social Sciences. 1985; 50(1): 1-8.

[51] Schroll M, Jónsson PV, Mor V, Berg K, Sherwood S. An international study of social engagement among nursing home residents. Age and Ageing. 1997; 26(Suppl 2): 55-9. http://dx.doi.org/10.1093/ageing/26.suppl_2.55

[52] Lai CK, Chi I \& Kayser-Jones J. A randomized controlled trial of a specific reminiscence approach to promote the well-being of nursing home residents with dementia. International Psychogeriatrics. 2004; 16(1): 33-49. http://dx.doi.org/10.1017/S1041610204000055

[53] Anthony JC, LeResche L, Niaz U, von Korff MR \& Folstein MF. Limits of the 'Mini-Mental State' as a screening test for dementia and delirium among hospital patients. Psychological Medicine. 1982; 12(2): 397-408. http://dx.doi.org/10.1017/S0033291700046730

[54] O'Connor DW, Pollitt PA, Hyde JB, Fellows JL, Miller ND, Brook CP \& Reiss BB. The reliability and validity of the Mini-Mental State in a British community survey. Journal of Psychiatric Research. 1989; 23(1): 87-96. http://dx.doi.org/10.1016/0022-3956(89)90021-6

[55] Chiu HFK, Lee HC, Chung WS, Kwong PK. Reliability and validity of the Cantonese version of the Mini-Mental State Examination - Preliminary study. Journal of Hong Kong College of Psychiatry. 1994; 4: 25-28.

[56] Darren G, Mallery P. IBM SPSS statistics 19: step by step: a simple guide and reference. 12th ed. Boston, Mass.: Pearson; 2012.

[57] Katz MH (ed.). Multivariable analysis: a practical guide for clinicians and public health researchers. Cambridge; New York: Cambridge University Press. 2011. http://dx.doi.org/10.1017/CBO9780511974175

[58] Allison PD. Logistic regression using the SAS system: Theory and application. New York, NY: John Wiley; 2001.

[59] Erdfelder E, Faul F, Buchner A. GPOWER: A general power analysis program. Behavior Research Methods, Instruments, \& Computers [Internet]. 1996; 28: 1-11. Avaible from http:/www.psycho.uni-duesseldorf.de/aap/projects/gpower/ http://dx.doi.org/10.3758/BF03203630

[60] Kanwar A, Singh M, Lennon R, Ghanta K, McNallan SM, Roger VL. Frailty and health-related quality of life among residents of long-term care facilities. Journal of Aging and Health, published online 25 June 2013. http://dx.doi.org/10.1177/0898264313493003

[61] Nurmikko TJ, Nash TP, Wiles JR. Recent advances: Control of chronic pain. British Medical Journal. 1998; 317(7170): 1438-1441. http://dx.doi.org/10.1136/bmj.317.7170.1438

[62] Levelle SG, Bean J, Bandeen-Roche K, Jones R, Hochberg M \& Guralnik JM (2002) Musculoskeletal pain and risk for falls in older disabled women living in the community. Journal of the American Geriatrics Society. 2002; 50(4): 671-678. http://dx.doi.org/10.1046/j.1532-5415.2002.50161.x

[63] Chen Q, Hayman LL, Shmerling RH, Bean JF, Leveille SG. Characteristics of Chronic Pain Associated with Sleep Difficulty in Older Adults: The Maintenance of Balance, Independent Living, Intellect, and Zest in the Elderly (MOBILIZE) Boston Study. Journal of the American Geriatrics Society. 2011; 59(8): 1385-1392. http://dx.doi.org/10.1111/j.1532-5415.2011.03544.x

[64] Ishine M, Okumiya K, Kimura Y, Kasahara Y, Wada T, Yamanaka G, Hotta N, Otsuka K, Murakami S \& Matsubayashi K. Subjective sleep disturbances were closely associated with comprehensive geriatric functions in dose-responsive manner in community-dwelling elderly people in Japan. Journal of the American Geriatrics Society. 2008; 56(8): 1571-1573. http://dx.doi.org/10.1111/j.1532-5415.2008.01761.x

[65] Babar SI, Enright PL, Boyle P, Foley D, Sharp DS, Petrovitch H, Quan SF. Sleep disturbances and their correlates in elderly Japanese American men residing in Hawaii. The Journals of Gerontology. Series A, Biological Sciences and Medical Sciences. 2000; 55(7): M406-M411. http://dx.doi.org/10.1093/gerona/55.7.M406

[66] Ohayon MM \& Vecchierini MF. Normative sleep data, cognitive function and daily living activities in older adults in the community. Sleep. 2005; 28(8): 981-989.

[67] Goldman SE, Stone KL, Ancoli-Israel S, Blackwell T, Ewing SK, Boudreau R, Cauley JA, Hall M, Matthews KA, Newman AB. Poor sleep is associated with poorer physical performance and greater functional limitations in older women. Sleep. 2007; 30(10): 1317-1326.

[68] Lo CMH, Lee PH. Prevalence and impacts of poor sleep on quality of life and associated factors of good sleepers in a sample of older Chinese adults. Health and Quality of Life Outcomes. 2012; 10(72): 1-7. 